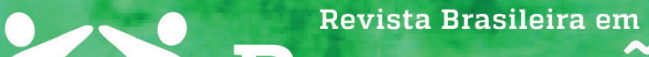

\section{PRODUÇÃO DE SENTIDOS PARENTAIS NO CUIDADO DE CRIANÇAS COM MICROCEFALIA POR VÍRUS ZIKA}

\section{Parental needs in the care for children with Zika virus-induced microcephaly \\ Producción de sentidos de los padres para el cuidado de niños con microcefalia por el virus Zika}

\section{Fabiane Elpídio de Sá}

Universidade Federal do Ceará - UFC - Fortaleza (CE) - Brasil

Núcleo de Tratamento e Estimulação Precoce - NUTEP - Fortaleza (CE) Brasil

\section{Micheline Maria Girão de Andrade}

Núcleo de Tratamento e Estimulação Precoce - NUTEP/UFC - Fortaleza (CE) Brasil

\section{Eve Mariana Coelho Nogueira}

Núcleo de Tratamento e Estimulação Precoce - NUTEP/UFC - Fortaleza (CE) Brasil

\section{Jovanka Soares Monteiro Lopes}

Núcleo de Tratamento e Estimulação Precoce - NUTEP/UFC - Fortaleza (CE) Brasil

\section{Antônia Paula Érika Pinheiro Silva}

Núcleo de Tratamento e Estimulação Precoce - NUTEP/UFC - Fortaleza (CE) Brasil

\section{Amanda Maria Veras de Assis}

Núcleo de Tratamento e Estimulação Precoce - NUTEP/UFC - Fortaleza (CE) Brasil

\section{RESUMO}

Objetivo: Identificar as necessidades parentais quanto ao cuidado para o desenvolvimento de lactentes e crianças com microcefalia causada pelo vírus da Zika (ZIKV). Métodos: Pesquisa qualitativa realizada em um centro de tratamento e estimulação precoce da Universidade Federal do Ceará, em Fortaleza, Brasil, no período de julho de 2016. Participaram do estudo 23 responsáveis, entre pais e familiares, de crianças com diagnóstico de microcefalia causada por Zika, cujos dados foram coletados por meio de grupos focais e analisados através da análise de conteúdo. Resultados: Os participantes relataram a necessidade de maior atenção, compreensão e apoio psicossocial por parte da instituição e dos profissionais envolvidos; mais conhecimento sobre o contexto geral da condição da criança; e intervenções educativas em saúde com acompanhamento continuado (follow-up) voltadas para as reais necessidades das crianças e suas famílias. Conclusão: Evidenciouse nos resultados a ausência e urgência da necessidade do desenvolvimento e implementação de estratégias e ações em saúde que favoreçam a escuta ativa e humanizada das famílias, reduzam o impacto negativo causado pela condição das crianças nas famílias e viabilizem um maior e melhor desenvolvimento de lactentes e crianças com microcefalia causada pelo vírus da Zika.

Descritores: Deficiências do desenvolvimento; Pais; Microcefalia; Zika Virus.

\section{ABSTRACT}

Objective: To identify parental needs with respect to the care for the development of infants and children with microcephaly caused by the Zika virus (ZIKV). Methods: Qualitative research conducted at a treatment and early stimulation center of the Federal University of Ceará, in Fortaleza, Brazil, in July 2016. A total of 23 guardians, either parents or relatives, of children diagnosed with Zika-induced microcephaly took part in the study, having their data collected by means of focus groups and analyzed through content analysis. Results: The participants reported the need for greater attention, understanding and psychosocial support from the institution and professionals involved; for more knowledge of the general context of the child's condition; and health education interventions with continuous follow-up focused on the real needs of the children and their families. Conclusion: The results evidenced the absence of and the urgent need for the development and implementation of health-related strategies and actions that favor the active and humanized listening of families, reduce the negative impact caused by the children's situation within the families and enable a greater and better development of infants and children with Zika virusinduced microcephaly.

Descriptors: Developmental Disabilities; Parents; Microcephaly; Zika Virus. 


\section{RESUMEN}

Objetivos: Identificar las necesidades de los padres sobre el cuidado con el desarrollo de lactantes y niños con microcefalia causada por el virus Zika (VZIK). Métodos: Investigación cualitativa realizada en un centro para tratamiento y estimulación temprana de la Universidad Federal de Ceará, Fortaleza, Brasil en el periodo de julio de 2016. Participaron del estudio 23 responsables entre ellos padres y familiares de niños con el diagnostico de microcefalia causada por el virus Zika cuyos datos fueron recogidos a través de grupos focales y analizados por el análisis de contenido. Resultados: Los participantes relataron la necesidad de más atención, comprensión y apoyo psicosocial de parte de la institución y de los profesionales involucrados; más conocimiento sobre el contexto general de la condición del niño; e intervenciones educativas en salud con el seguimiento continuado (follow-up) dirigidos para las reales necesidades de los niños y sus familias. Conclusión: En los resultados se evidenció la ausencia y urgencia de la necesidad del desarrollo e implementación de estrategias y acciones de salud que favorezcan la escucha activa y humanizada de las familias, reduzcan el impacto negativo causado por la condición de los niños en las familias y que viabilicen un mejor y mayor desarrollo de los lactantes y niños con microcefalia causada por el virus Zika.

Descriptores: Discapacidades del Desarrollo; Padres; Microcefalia; Virus Zika.

\section{INTRODUÇÃO}

Um grande surto de infecção por Zika vírus (ZIKV) eclodiu no Nordeste do Brasil nos últimos meses de 2015(1). Em novembro deste ano, identificou-se a infecção por ZIKV no líquido amniótico de uma gestante brasileira no quinto mês de gestação, cujo feto apresentava microcefalia ${ }^{(2,3)}$. No mesmo mês, um virologista brasileiro detectou a presença desse vírus em exames de sangue e tecidos de dois natimortos com microcefalia, reforçando e confirmando a suspeita de sua associação com malformações congênitas ${ }^{(4)}$.

Ainda em novembro de 2015, surgiu o termo "síndrome associada à infecção congênita por Zika", ou simplesmente "Zika congênito"(5). Estudos foram publicados nos meses consecutivos confirmando definitivamente a associação. Apenas em 2016, porém, foi reconhecida essa associação pela Organização Mundial de Saúde (OMS), tornando o Brasil pioneiro em relacionar a infecção viral a defeitos congênitos e várias manifestações cerebrais, incluindo a microcefalia em recém-nascidos ${ }^{(6-8)}$. Diferentes publicações descreveram os casos iniciais em Pernambuco, Brasil, com achados clínicos de imagens e laboratoriais, e outros ainda continuam em fase de construção para um melhor entendimento da condição ${ }^{(9-11)}$.

O ZIKV é transmitido por mosquitos da espécie Aedes, também relacionados com a febre amarela, a dengue, o vírus do Nilo Ocidental e a encefalite japonesa. Ele foi identificado pela primeira vez em 1947, no Vale do Zika, em Uganda. A infecção produz sintomas leves, como febre, erupção cutânea e artralgia, e emergiu da obscuridade, chamando atenção global por sua associação com a suspeita de uma "Síndrome congênita por vírus Zika"(12-14).

A microcefalia é a característica clínica mais comumente observada na Síndrome congênita por vírus Zika. É caracterizada pela medida do crânio ou perímetro cefálico menor que menos dois (-2) desvios-padrões abaixo da média específica para o sexo e idade gestacional. A medida do perímetro cefálico é realizada com fita métrica flexível e não elástica. Mede-se o diâmetro do crânio em sua maior circunferência, com a fita ao redor da cabeça, disposta na testa, acima dos olhos, e das orelhas, pela parte mais saliente do lado posterior do crânio. Em bebês não prematuros, esse perímetro deve ser maior do que $32 \mathrm{~cm}$ (com pequena variação pela idade gestacional e sexo). O perímetro cefálico aumenta quase linearmente até 37-38 semanas de gestação( ${ }^{(15)}$. Desse modo, é imprescindível o treinamento do pessoal que realiza a medição e, quando for limítrofe ou anormal, deve ser repetida.

A expansão súbita da epidemia por ZIKV pode vir a ser uma das principais causas de distúrbios neuropsicomotores e incapacidades em uma geração de recém-nascidos acometidos por microcefalia secundária à infecção materna por vírus Zika, representando um grande fardo para as famílias envolvidas e alto encargo socioeconômico para os países afetados ${ }^{(13)}$.

Inúmeras crianças e famílias em todas as Américas foram impactadas negativamente em sua qualidade de vida pela epidemia do $\mathrm{ZIKV}^{(4)}$. Esse número continua a crescer, demonstrando que as repercussões no desenvolvimento em longo prazo dessas crianças e o efeito sobre suas famílias são ainda, em grande parte, desconhecidos ${ }^{(16,17)}$.

Os óbitos fetais e neonatais, ocorridos de 2015 até maio de 2017, somando ao todo 366 óbitos suspeitos de ZIKV, encontravam-se em monitoramento, dos quais 270 (73,8\%) estavam em investigação, 49 (13,4\%) foram desconsiderados, 30 $(8,2 \%)$ foram confirmados e $7(1,9 \%)$ foram tidos como prováveis para relação com infecção congênita durante a gestação. Dez óbitos notificados (2,7\% do total) foram excluídos após judiciosa investigação por não preencherem as definições de caso vigentes. A maioria dos óbitos notificados agrupa-se no Nordeste do Brasil (54,9\%), seguido pela Região Sudeste (25,7\%) e Centro-Oeste (10,1\%). Os cinco estados com maior número de casos notificados em monitoramento são: Pernambuco (109), Rio de Janeiro (36), São Paulo (27), Ceará (25) e Minas Gerais (25) ${ }^{(18)}$.

Diante desse quadro, reflete-se que a própria gestação já é um período de modificações relevantes na vida de uma mulher e de sua família, com novos papéis para o pai e a mãe. Se essa gestante com suspeita de ZIKV, com possibilidade de que sua criança padeça de alterações no desenvolvimento e/ou tenha lesões, como as cerebrais, não tiver o apoio e o cuidado de um parceiro(a) ou de um familiar próximo, ou se a equipe de saúde não discutir sobre a doença, ela poderá sofrer muito, podendo adoecer e desenvolver alterações físicas, psíquicas e sociais em um momento em que necessita cuidar de si e do(s) filho(s) ${ }^{(19)}$. 
Portanto, a pesquisa em questão torna-se fundamental para aumentar a discussão coletiva sobre o papel dos pais e cuidadores no tratamento dessas crianças, auxiliando na compreensão sobre a doença para um melhor entendimento sobre as reais necessidades dessas famílias e suas crianças. Espera-se que os resultados possam servir como guia para o planejamento de políticas e programas de estratégias de orientação e abordagem em saúde de famílias nessa condição, assegurando um plano de cuidados eficaz e eficiente para a continuidade do tratamento e a promoção de melhores resultados na saúde física e psicológica de pais e familiares de crianças com microcefalia por ZIKV.

Assim, diante desse contexto, questiona-se: Quais as necessidades parentais quanto ao cuidado para o desenvolvimento de lactentes e crianças com microcefalia por vírus Zika? Dessa forma, o estudo tem como objetivo identificar as necessidades parentais quanto ao cuidado para o desenvolvimento de lactentes e crianças com microcefalia por vírus Zika (ZIKV).

\section{MÉTODOS}

A pesquisa possui abordagem qualitativa e caráter descritivo ${ }^{(20)}$ e considera os Padrões para o Relatório de Pesquisa Qualitativa (SRQR) ${ }^{(21)}$. Desenvolveu-se no Núcleo de Tratamento e Estimulação Precoce (NUTEP), instituição sem fins lucrativos criada em 1987, na cidade de Fortaleza, Ceará, que funciona no Complexo Hospitalar da Faculdade de Medicina da Universidade Federal do Ceará (UFC) e tem como missão assistir crianças na faixa etária de 0-12 anos em risco de/ou com transtornos no desenvolvimento, assim como suas famílias, através de uma equipe de saúde multiprofissional e interdisciplinar especializada, envolvendo médicos, enfermeiras, fisioterapeutas, fonoaudiólogas, terapeutas ocupacionais, psicólogas e assistentes sociais; com enfoque na realidade socioeconômica e emocional da clientela, propondo-se a ser um Centro de Referência para pesquisa e formação profissional ${ }^{(22)}$.

O estudo desenvolveu-se no período de julho de 2016, após a análise de 35 prontuários médicos de crianças acompanhadas pelo NUTEP que foram cedidos pela instituição. As pesquisadoras convidaram os pais a participarem do estudo na própria instituição, no momento de entrega das crianças para o atendimento multidisciplinar, sendo incluídos como participantes no estudo os pais/familiares de lactentes e crianças com diagnóstico clínico de microcefalia associada à infecção materna por vírus Zika inseridos no serviço do NUTEP a menos de seis meses e que concordaram em participar efetivamente de três encontros grupais, a serem previamente agendados pela equipe de pesquisadoras do NUTEP. Ressalta-se que foram excluídos os participantes que não compareceram a pelo menos dois encontros grupais. Assim, o estudo teve como amostra 23 pais/familiares que atenderam aos critérios de inclusão e que aceitaram participar da pesquisa, assinando os Termos de Consentimento Livre e Esclarecido (TCLE) com autorização de gravação e uso de áudio e imagem.

Utilizou-se como método de investigação e coleta de dados os grupos focais; envolvendo o diálogo entre os pais e familiares das crianças e trazendo para a roda, de modo participativo, as falas dos participantes da pesquisa ${ }^{(23,24)}$; produzindo e fazendo circular relatos peculiares, por meio dos quais os indivíduos se reconhecem e são reconhecidos ${ }^{(25,26)}$.

Realizaram-se três grupos focais, executados em auditório adequadamente preparado e cedido pela instituição NUTEP. Cada um teve duração de 30 minutos. Todos os dados relevantes dos discursos eram armazenados através de recursos de áudio e vídeo em gravação e em diários de campo para análise posterior. Cada grupo focal era presidido por três moderadoras pesquisadoras: (01) uma fisioterapeuta, (01) uma discente do Curso de Fisioterapia da UFC e (01) uma psicóloga. Os participantes eram questionados pelas três moderadoras sobre suas experiências de vida e ideias sobre crescimento, desenvolvimento, microcefalia e orientações terapêuticas; como também sobre suas maiores dificuldades nos cuidados prestados às crianças.

O intuito primordial dos grupos focais era, através da escuta ativa e humanizada das falas parentais, explorar o íntimo das famílias, o "antes nunca dito", "o sentido, mas não expressado", "o negado"; buscando, dentro de sua especificidade e complexidade, o desenvolvimento de um olhar mais global, amplo e atencioso sobre os pais e familiares das crianças com microcefalia por ZIKV.

O material coletado passou por análise minuciosa de conteúdo, a qual foi divida em etapas de pré-análise, exploração do material, tratamento dos resultados e interpretação ${ }^{(27)}$. Primeiro, os relatos gravados foram ouvidos e transcritos na íntegra. Em seguida, divididos em categorias para posterior significação e interpretação dos dados. A partir de então, os pontos críticos das falas e posturas parentais diante do enfrentamento da condição vivida, dos questionamentos lançados e da partilha de conceitos e experiências expostas nos grupos focais foram determinados a partir de uma visão biopsicossocial do indivíduo, procurando compreender e conhecer mais profundamente o que envolve o âmbito parental e os processos de cuidado desenvolvidos pelas famílias no desenvolvimento da criança com microcefalia por ZIKV.

Extraíram-se duas categorias: Microcefalia por ZIKV e as mudanças no contexto familiar, e Serviço de estimulação e os cuidados com o crescimento e desenvolvimento dos bebês.

A pesquisa seguiu as determinações éticas da Resolução no 466/12 do Conselho Nacional de Saúde sobre pesquisa envolvendo seres humanos, sendo executada após aprovação do Comitê de Ética em Pesquisa (COMEPE) da Universidade Federal do Ceará - UFC, sob o Parecer $n^{\circ}$ 1684521. Todos os participantes da pesquisa tiveram direito ao sigilo e suas identificações preservadas. Para isso, foram utilizadas designações tais como: Participante 01, Participante 02 ... Participante 23. 


\section{RESULTADOS E DISCUSSÃO}

A seguir, as categorias temáticas, com as falas dos participantes, são apresentadas.

\section{Microcefalia por vírus Zika e as mudanças no contexto familiar}

Nessa categoria, foram explanados pelos participantes sentimentos de angústia, medo e frustração, tanto pela perda do bebê esperado, entendido como o filho ideal pelos pais e familiares, quanto pelas mudanças ocorridas no contexto familiar com a chegada de um filho com deficiência, que exige maiores gastos econômicos e mudanças sociais para essas famílias, incluindo-se geralmente a necessidade de um dos pais deixar de trabalhar e/ou estudar. Acrescenta-se ainda que o apoio familiar é restrito, ou até ausente, e muitas famílias são consideradas monoparentais, isto é, a mãe é a única provedora e a presença de um filho com microcefalia transforma todo o contexto familiar.
(...) Eu tinha tudo sobre controle e a minha vida se transformou (...) Eu entrei em outro mundo (...) (Participante 01).
(...) Eu estou sozinha e ninguém me ajuda (...) Eu sinto que estou mudando e não quero mudar (...) Tudo mudou lá em casa (...) O meu outro filho mudou muito também (...) Acho que ele está precisando de ajuda psicológica (...) Eu achava que estava tudo sob controle, mas não está (...) (Participante 05).

Ter uma criança com deficiência no desenvolvimento neuropsicomotor, uma condição que pode ser perene ao longo da vida, com a perspectiva de um futuro indesejado e não programado, transforma-se em um poderoso fator estressor para os pais/ familiares, pois são incapazes de relaxar, devido às obrigações diárias para com os filhos, ao tempo disponibilizado para os tratamentos médicos no hospital e em casa, não havendo tempo hábil para interesses pessoais e atividades de lazer. Isso pode levar os pais à perda de controle, incapacidade física e/ou emocional, estresse crônico e repetido, ansiedade e doenças físicas, incluindo a doença cardiovascular e a deficiência imunológica ${ }^{(28)}$.

As falas indicam a indispensabilidade de um maior apoio psicológico e social para essas famílias, incluindo visitas domiciliares da equipe multidisciplinar. Por se tratar de uma condição crônica, as crianças necessitam de altos níveis de apoio parental, social e educacional, enfatizando que continuarão a exigir indefinidamente altos níveis de cuidados básicos pessoais aos cuidadores, no caso, os pais e familiares envolvidos; isso pode gerar prejuízos na saúde e qualidade vida dos pais, incluindo sintomas de depressão, ansiedade e dores musculares ${ }^{(17,29)}$.

A insegurança foi relatada pelos participantes no que concerne ao conhecimento com profundidade pela equipe de saúde sobre a "nova" microcefalia pelo mosquito, conforme relatos dos familiares, por ser uma doença de causas e consequências diferentes das "outras microcefalias":

(...) Nós, pais, avós e família, não sabemos o que pode ser o futuro da criança (...) nem vocês, da saúde conhecem ainda, imagine nós (...) Eu sei que essa doença é totalmente nova diante das outras microcefalias (...) (Participante 04).

(...) Estou aprendendo a observar meu filho, um dia de cada vez, o que importa é o hoje (...) Se tudo é novo para vocês, imagina para nós (...) (Participante 20).

Não se pode esquecer que, por ser uma condição da atualidade emergencial e relativamente nova, as informações sobre o ZIKV e seus efeitos em mulheres grávidas, fetos, recém-nascidos, lactentes e crianças, incluindo outras complicações neurológicas e comorbidades associadas, são gradualmente conhecidas e disponibilizadas para a sociedade, à medida que as pesquisas avançam, o que causa bastante desconforto na sociedade, principalmente nas equipes de saúde e famílias envolvidas.

Sabe-se, hoje, que a Síndrome congênita ocasionada por ZIKV possui um padrão reconhecido de anomalias congênitas associado à infecção por esse vírus durante a gravidez materna, que inclui microcefalia, calcificações intracranianas, outras anomalias cerebrais, anomalias oculares, e outras ${ }^{(30)}$. Manter as famílias e/ou cuidadores informados e atualizados sobre uma condição a que estão expostos, seus fatores de risco e consequências, é de extrema importância, não só por razões de saúde pública, mas também por propiciar a geração de novos conhecimentos e empoderamento dessas pessoas em suas comunidades ${ }^{(31)}$.

Nesse contexto, ainda se mostra insuficiente a capacidade de enfrentamento e preparo das equipes de saúde para lidar com essas famílias, tão fragilizadas. Mostra-se insuficiente, sobretudo, a capacidade de encarar o desafio de implementar a "escuta ativa e humanizada" em suas práticas clínicas. Além disso, avaliações e métodos de intervenção contínuos, eficazes e significativos para as famílias.

Embora reconhecendo que as evidências científicas sobre o tema ainda sejam restritas, é fundamental que os provedores de cuidados à saúde mantenham uma comunicação horizontal e eficaz junto à comunidade acerca dos riscos relacionados com a transmissão do vírus da Zika e suas consequências ${ }^{(31)}$, desenvolvendo ações intersetoriais de educação em saúde, capazes de envolver a comunidade, mudar percepções e comportamentos, promovendo uma transformação social favorável ${ }^{(32)}$.

O cansaço e a dificuldade das mães em administrar simultaneamente os afazeres domésticos; cuidar da criança, do marido e de outros filhos; lidar com os comentários da sociedade e ainda com a exposição exagerada do assunto na mídia são evidenciadas nas falas: 
(...)Me sinto cansada, exausta mesmo (...) eu nem lembro de mim... de quem eu sou (...) (Participante 9).

(...) A mídia e a sociedade contribuem muito para a dificuldade de enfrentamento dessa doença, pois essa exposição dos nossos filhos acaba com a gente (...) Nos sentimos invadidos e amedrontados (...) (Participante 17).

É necessária a exigência de cautela, vigilância e muita responsabilidade, principalmente por parte dos profissionais de serviços de saúde no que diz respeito à exposição midiática exacerbada sobre os familiares de crianças com microcefalia por ZIKV através das agências e mídias sociais, pois podem fornecer muitas vezes informações inconsistentes ou contraditórias, com grande poder de afligir e estigmatizar essas famílias. As notícias veiculadas nos meios de comunicação sobre o assunto têm repercutido amplamente na mídia brasileira, ocasionando um impacto social e emocional devastador nas famílias acometidas ${ }^{(3,3,34)}$.

Pais de crianças em condição de deficiência e cronicamente doentes são um grupo vulnerável em relação à saúde e qualidade de vida. A alta carga de cuidados exigida aos pais e/ou cuidadores está associada à menor participação social, maiores encargos financeiros e maior necessidade de ajuda no agregado familiar, o que contribui significativamente no aumento de riscos para a saúde ${ }^{(35)}$.

Tendo em vista as várias lacunas ainda existentes no conhecimento científico acerca da infecção pelo ZIKV, deve ser ressaltado para a sociedade que as informações e recomendações divulgadas são passíveis de revisão e mudanças com eventuais incorporações de novos conhecimentos e outras evidências, bem como da necessidade de adequações das ações de vigilância em cenários epidemiológicos futuros e estudos mais aprofundados ${ }^{(36,37)}$.

\section{Serviço de estimulação e os cuidados com o crescimento e desenvolvimento dos bebês}

Nessa categoria, que versa sobre o serviço de intervenção precoce e sua relação com o crescimento e desenvolvimento dos bebês, os discursos parentais referenciaram relatos de medo e insegurança quanto aos estímulos; questionamentos sobre materiais e cuidados propícios e/ou viáveis para com a criança no ambiente domiciliar; e muitas dúvidas quanto ao quadro, prognóstico, evolução motora e intelectual da criança com microcefalia:

\section{(...) Será que estou fazendo certo? Eu vi na televisão que quanto mais estimular melhor (...) (Participante 08).}

(...) Eu tenho muitas dúvidas (...) será que quanto mais estimularmos melhor para eles? (...) Isso também pode trazer problemas, pois eles choram tanto e eu tenho medo de acontecer alguma coisa lá dentro da cabeça dele (...) (Participante 16).

\section{(...) Será que eles não sentem dor de cabeça por causa da microcefalia? (...) (Participante 01).}

Promover autoconfiança e proporcionar apoio psicológico adequado para um melhor desempenho do dia a dia familiar pode intensificar o empoderamento dos pais, propiciando bem-estar, o enfrentamento saudável da condição de vida, melhora no acesso e no apoio aos serviços necessários e facilidade na prestação de melhores serviços para as famílias ${ }^{(38)}$. No que se refere às abordagens centradas na família, o empoderamento parental é essencial, principalmente oferecendo condições necessárias para que os pais sejam capazes de se autoavaliar no que diz respeito à gestão de seus filhos, estando diretamente relacionado aos recursos internos e à capacidade de apropriação da vida ${ }^{(39)}$.

Ficou clara, no presente estudo, a necessidade e o desejo por um olhar mais atencioso por parte da equipe de saúde, oferecendo estratégias de orientação e educação em saúde que incluam a capacitação parental no contexto de crianças com microcefalia por ZIKV:

(...) Precisamos de uma oficina que nos ajude a construir materiais de apoio nos cuidados diários com o bebê (...) Seria uma forma de nos orientar como fabricar brinquedos e estimular a criança em casa (...) Esse pouco tempo que entramos nas salas não dá para aprender tudo (...) (Participante 03).

(...) Preciso entrar no atendimento para ver a estimulação e tentar fazer em casa com ele (...) ( Participante 07).

(...) Precisamos saber o que fazer em casa para continuar o tratamento (...) porque, às vezes, a criança vem para clínica, fica irritada e tensa na hora do atendimento e não aproveita muito (...) Eu fico preocupada (...) (Participante 09).

As alterações mais comumente associadas à microcefalia estão relacionadas ao déficit intelectual e outras condições, que incluem: irritabilidade; convulsões; epilepsia; paralisia cerebral; atraso no desenvolvimento de linguagem e/ou motor; desordens oftalmológicas, cardíacas, renais e do trato urinário; entre outras ${ }^{(40)}$. É de extrema importância o envolvimento dos pais e familiares no tratamento e acompanhamento da criança em condição de deficiência, pois o ambiente familiar e social é o mais rico em estímulos para a criança. A equipe de saúde multiprofissional envolvida deve informar à família sobre os aspectos e desdobramentos da doença, orientando-os sobre as atividades de vida diária e como utilizar alguns momentos, como o banho, vestuário, alimentação, autocuidado e, principalmente, as brincadeiras, para estimular o desenvolvimento neuropsicomotor ${ }^{(37)}$.

As famílias da atual pesquisa esboçaram em suas falas a dificuldade para lidar com o choro, a irritação exacerbada e a rigidez da criança, principalmente durante as atividades de vida prática e diária (banho, limpeza higiênica, troca de fraldas). De acordo com os relatos, o quadro de hipertonia aumenta muito quando o lactente está em um momento de irritação e choro. 
(...) Tenho muita dificuldade quando vou dar um banho nele, ele fica todo esticado, não sei o que fazer, nem como segurálo (...) (Participante 07).

(...) Meu Deus, que choro é esse!? (...) É desesperador, doutora. (...) Não sabemos o que é! (...) É da microcefalia, o choro? (...) E, quando eu me desespero, ela fica ainda mais irritada. (...) (Participante 10).

Pais e/ou cuidadores exercem um papel de agentes cooperadores para as modificações do comportamento motor no desenvolvimento de crianças com incapacidades motoras. Por isso, oferecer orientações contínuas e apropriadas, além do acompanhamento consistente dessas famílias e/ou cuidadores, almejando uma adesão e participação ativa no tratamento dessas crianças, pode gerar resultados satisfatórios no desempenho de suas habilidades funcionais ${ }^{(41)}$.

Os cuidadores assumem o controle da manutenção dos cuidados da criança, mas geralmente desconsideram as prováveis intercorrências da condição clínica. O grande desafio para a equipe ainda é prover continuamente orientações necessárias ao manejo da condição pela família. É importante que as instituições e equipes multiprofissionais que atendem recém-nascidos, lactentes e crianças com microcefalia insiram em seus processos de cuidado alguns aspectos, tais como: envolvimento da família e trabalho de equipe com interdisciplinaridade e plano terapêutico de intervenção precoce, principalmente na primeiríssima infância (0 a 3 anos $)^{(42)}$.

A comunicação e o apoio certificam o desenvolvimento de relações de confiança entre as famílias e os diferentes agentes envolvidos, criando, assim, um espaço para a reflexão em torno da intervenção precoce na infância e estratégias de intervenção eficazes em casos de risco estabelecido ${ }^{(43)}$.

As falas analisadas no presente estudo revelaram a necessidade de orientações acerca da alimentação dos lactentes, sobretudo na condução do aleitamento materno, desmame, tipos de alimentos, espaçamento entre as dietas, introdução de complementos e uso de chupetas adequadas quando o bebê não amamenta exclusivamente. Além disso, emergiu das palestras a necessidade específica das famílias em aprender técnicas de primeiros socorros, principalmente para reverter os engasgos, ocasionados pela disfagia, e manobras de limpeza e higiene das vias aéreas nas crianças, pois os bebês apresentam refluxo gástrico e dificuldade em aceitar a alimentação (principalmente o leite), tornando-se difícil alimentá-los adequadamente. Pode-se apreender nas falas muitas dúvidas, hesitação e extrema ansiedade das famílias em lidar com esse refluxo e as dietas recomendadas:

(...) Eu tenho muito medo de alimentar o meu filho. Quando ele vai comer, eu saio de perto (...) (Participante 04).

(...) Uma vez, ele engasgou e quase sufocou (..) fiquei muito mal, queria sumir (...) Não quero passar mais por isso não, de jeito nenhum (...) (Participante 11).

(...) Eu estou amamentando, mas ele chora muito (...) Será que ele sente dor? (...) Dizem que sente, por causa do refluxo (...) Quando eu posso dar outro alimento? (...) O que faço se ele engasgar? (...) (Participante 14).

Um programa de reabilitação eficaz para crianças com distúrbios neuropsicomotores precisa levar em conta os altos níveis de fadiga, depressão e ansiedade das mães dessas crianças, as quais devem prioritariamente ser acompanhadas e apoiadas psicologicamente mais de perto pelas equipes de saúde ${ }^{(44)}$.

Também foram expressas dúvidas, medos e anseios sobre vacinação e puericultura na atual investigação, assim como houve relatos sobre o receio e até recusa de profissionais de saúde da Unidade de Atenção Primária à Saúde em vacinar as crianças ao saberem sobre a condição que elas ocupam:

(...) Fui levar minha filha para o posto e a auxiliar de enfermagem me disse que não tinha como dar a vacina dela, porque ela era especial (...) (Participante 16).

(...) Eu não sei nada sobre as vacinas dela (...) Pode vacinar normalmente como as outras crianças, não é? (...) Ela não tem acompanhamento além do NUTEP (...) (Participante 04).

A compreensão e o compartilhamento de experiências das dificuldades vivenciadas por cuidadores de pessoas em condição de deficiência pode desenvolver processos facilitadores durante o curso da experiência da doença, tanto para o próprio cuidador quanto para a equipe de saúde ${ }^{(45)}$.

Percebeu-se, no presente estudo, a urgência por um apoio específico relacionado com a assistência à puericultura, ou aconselhamento parental sobre os problemas da criança, somando-se ao apoio psicoemocional ou instrumental geral e ao apoio familiar. Dessa forma, beneficiará diretamente as famílias e contribuirá significativamente para a redução dos níveis de estresse materno e familiar. Pesquisa relata a necessidade urgente e insatisfeita de pais e famílias de crianças com deficiências por um atendimento mais abrangente, envolvendo grupos e redes de apoio psicossocial e financeiro, assistência domiciliar e viabilidade dos cuidados domiciliares infantis para uma melhor continuidade do tratamento ${ }^{(46)}$.

Através dos relatos pode-se notar que as famílias da pesquisa em questão passam por situações de enfrentamento perante a deficiência da criança ocasionada pela microcefalia, como também a aceitação da responsabilidade para com os cuidados com a criança, mesmo que existam sentimentos que ultrapassem essas questões e que afligem as famílias:

(...) Quando ele nasceu, eu não sabia, mas quando eu o vi, eu disse: meu Deus, ele é só uma criança, um bebê (...) (Participante 05). 
(...) Eu sou uma mãe especial, fui escolhida para cuidar dela (...) e essa equipe maravilhosa me faz continuar (...) (Participante 08).

(...) Ele é tudo para mim (...) é a alegria da casa, da família e dos irmãos (...) Todos cuidam dele (...) e eu vou acreditar nas potencialidades dele (...) Um dia de cada vez (...) (Participante 10).

Os pais de crianças com deficiência tornam-se porta-vozes para seus filhos. A incapacidade dos filhos e a complexidade da condição fazem os pais indispensáveis na compreensão e concepção das necessidades e desejos de $\operatorname{seus~filhos~}^{(16,27,44)}$.

As famílias, diante do enfrentamento de sua condição de vida, reavaliam seus conceitos iniciais acerca das deficiências, aprendem a valorizar as potencialidades da criança e requisitam contínuos reforços em suas estimas pessoais e que as auxiliem no aprendizado de como lidar com as suas limitações. Autores descrevem a condição de se ter um filho em condição de deficiência como um momento delicado para as famílias, no qual os pais geralmente buscam estratégias para melhor lidar com a situação e, para isso, o apoio profissional é de extrema importância. Portanto, as equipes de saúde envolvidas devem estar preparadas para oferecer o suporte necessário ${ }^{(40,47)}$.

Entender-se como responsável por uma criança com distúrbios no desenvolvimento é uma situação complexa de intensas mudanças, descobertas e aprendizados. Abordar a história de vida de famílias nessa condição, isto é, seus sentimentos, medos, ansiedades e desejos nessa circunstância, é certamente uma grande oportunidade para instituições e profissionais da saúde investirem em ações de educação, auto-gestão e cuidado em saúde, com intervenções centradas nas necessidades parentais. A escassez de medidas específicas, que identifiquem adequadamente as necessidades dos pais de crianças nessa condição, é notória ${ }^{(48)}$. Dessa forma, os profissionais de saúde que atendem famílias podem e devem reforçar os recursos parentais, apoiando o envolvimento deles na tomada de decisões relativas à sua criança e vida familiar, contribuindo assim significativamente para a consolidação do bem-estar de todos os envolvidos ${ }^{(38)}$.

Com base nas descobertas do atual estudo, corrobora-se que os profissionais de saúde podem e devem subsidiar a capacitação parental de forma permanente e continuada, reforçando o empoderamento dos pais e familiares de crianças com microcefalia por ZIKV com de uma abordagem contínua através de visitas domiciliares e do envolvimento dos pais em cada fase do tratamento dos filhos ${ }^{(41)}$.

Para que isso ocorra, os profissionais de saúde devem buscar entender a especificidade do contexto familiar, principalmente em ambiente domiciliar, e construir uma assistência em que as respostas do serviço estejam ao nível das necessidades parentais e da capacidade em atendê-las, para que, assim, essas famílias possam dar a continuidade viável e apropriada ao cuidado e possam exercer uma maior influência sobre os serviços prestados as suas crianças. Como limitações do presente estudo, pode-se mencionar que, em relação à amostra, houve uma maior participação de mães do que de pais e outros familiares.

\section{CONCLUSÃO}

Embora o apoio das instituições às famílias frente às alterações do desenvolvimento dos lactentes com microcefalia e suas possíveis comorbidades mostre-se de forma incondicional e pareça abrangente, evidenciou-se, nos resultados da presente pesquisa, que não. Há ausência e urgente necessidade no desenvolvimento e implementação de estratégias de investigação e de ações em saúde por parte das instituições e profissionais envolvidos nesse contexto. As estratégias e ações devem favorecer a escuta ativa e humanizada das famílias, de modo a priorizar suas reais necessidades de suporte para os cuidados com a criança, principalmente através de intervenções parentais educativas em saúde e visitas domiciliares de forma permanente e com garantia de acompanhamento (follow-up), com a finalidade prioritária de melhorar a assistência, reduzir o impacto negativo causado pela condição das crianças nas famílias e viabilizar um maior e melhor desenvolvimento de lactentes e crianças com microcefalia por Zica, focando na certeza de que se trata de um agravo de alta relevância para a saúde coletiva.

\section{AGRADECIMENTOS}

Aos pais, familiares e profissionais de saúde e ao Núcleo de Tratamento e Estimulação Precoce (NUTEP-CE).

\section{REFERÊNCIAS}

1. Ministério da Saúde (BR), Secretaria de Vigilância em Saúde. Vírus Zika no Brasil: a resposta do SUS [Internet]. Brasília: Ministério da Saúde; 2017 [acesso em 2017 Set 4]. Disponível em: http://bvsms.saude.gov.br/bvs/publicacoes/virus_zika_ brasil_resposta_sus.pdf

2. Oliveira Melo AS, Malinger G, Ximenes R, Szejnfeld PO, Alves Sampaio S, Bispo de Filippis AM. Zika virus intrauterine infection causes fetal brain abnormality and microcephaly: tip of the iceberg? Ultrasound Obstet Gynecol. 2016;47(1):6-7.

3. Hussain HF, Hafiz MY, Hussain SA. Rumor has it; the truth behind Zika virus. J Infect Public Health. 2017;10(1):135-6. 
4. Pan American Health Organization, World Health Organization. Zika suspected and confirmed cases reported by countries and territories in the Americas Cumulative cases, 2015-2017. Washington: PAHO/WHO; 2017 [acesso em 2017 Set 4 ]. Disponível em: http://www2.paho.org/hq/index.php?option=com_docman\&task=doc_view\&Itemid=270\&gid=38901\&la $\mathrm{ng}=\mathrm{en}$

5. Brito C. Zika Virus: a new chapter in the history of medicine. Acta Med Port. 2016 28(6):679-80.

6. Butler D. Zika and birth defects: what we know and what we don't. Nature. 2016 Mar [acesso em 2017 Set 4]. Disponível em: http://www.nature.com/doifinder/10.1038/nature.2016.19596

7. Cui L, Zou P, Chen E, Yao H, Zheng H, Wang Q, et al. Visual and motor deficits in grown-up mice with congenital zika virus infection. EbioMedicine [Internet]. 2017 [acesso em 2017 Set 4];20:193-201. Disponível em: http://www-sciencedirectcom.ez11.periodicos.capes.gov.br/science/article/pii/S2352396417301846

8. Freitas BP, Ko AI, Khouri R, Mayoral M, Henriques DF, Maia M, et al. Glaucoma and congenital Zika Syndrome. Ophthalmology [Internet]. 2017 [acesso em 2017 Set 4];124(3):407-8. Disponível em: http://linkinghub.elsevier.com/ retrieve/pii/S0161642016310557

9. Hazin AN, Poretti A, Cruz DCS, Tenorio M, Van der Linden A, Pena LJ, et al. Computed tomographic findings in microcephaly associated with Zika Virus. N Engl J Med [Internet]. 2016 [acesso em 2017 Set 4];374:2193-5. Disponível em: http://www.nejm.org/doi/10.1056/NEJMc1603617

10. Microcephaly Epidemic Research Group. Microcephaly in infants, Pernambuco State, Brazil, 2015. Emerg Infect Dis [Internet]. 2016 [acesso em 2017 Set 4];22(6):1090-3. Disponível em: http://wwwnc.cdc.gov/eid/article/22/6/16-0062_ article.htm

11. Cordeiro MT, Pena LJ, Brito CA, Gil LH, Marques ET. Positive IgM for Zika virus in the cerebrospinal fluid of 30 neonates with microcephaly in Brazil. Lancet [Internet]. 2016 [acesso em 2017 Set 4];387(10030):1811-2. Disponível em: http:// linkinghub.elsevier.com/retrieve/pii/S0140673616302537

12. Cofré F. Infección intrauterina por virus Zika y microcefalia. Rev Chil Infectol. 2016;33(1):96.

13. Chan JFW, Choi GKY, Yip CCY, Cheng VCC, Yuen K-Y. Zika fever and congenital Zika syndrome: an unexpected emerging arboviral disease. J Infect [Internet]. 2016 [acesso em 2017 Set 4];72(5):507-24. Disponível em: http://linkinghub.elsevier. com/retrieve/pii/S016344531600061X

14. Baud D, Gubler DJ, Schaub B, Lanteri MC, Musso D. An update on Zika virus infection. Lancet [Internet]. 2017 [acesso em 2017 Set 4]. Disponível em: http://linkinghub.elsevier.com/retrieve/pii/S0140673617314502

15. World Health Organization. The WHO child growth standards [Internet]. Geneva: WHO; 2016 [acesso em 2017 Set 4]. Disponível em: www.who.int/childgrowth/en/

16. Kapogiannis BG, Chakhtoura N, Hazra R, Spong CY. Bridging knowledge gaps to understand how zika virus exposure and infection affect child development. JAMA Pediatr [Internet]. 2017[acesso em 2017 Set 4];171(5):478. Disponível em: http://archpedi.jamanetwork.com/article.aspx?doi=10.1001/jamapediatrics.2017.0002

17. Jansen SLG, van der Putten AAJ, Vlaskamp C. What parents find important in the support of a child with profound intellectual and multiple disabilities. Child Care Health Dev [Internet]. 2013 [acesso em 2017 Set 4];39(3):432-41. Disponível em: http://doi.wiley.com/10.1111/j.1365-2214.2012.01381.x

18. Ministério da Saúde (BR), Secretaria de Vigilância em Saúde. Monitoramento integrado de alterações no crescimento e desenvolvimento relacionadas à infecção pelo vírus Zika e outras etiologias infecciosas, até a Semana Epidemiológica 20/2017. Boletim Epidemiol. 2017;48(19):1-9.

19. Feijó MR. Gestação e zika: muita coisa para uma mãe só. Fórum: Suplemento do Jornal Unesp [Internet]. 2016 Abr, p. 3 [acesso em 2017 Jul 20]. Disponível em: https://repositorio.unesp.br/bitstream/handle/11449/138718/JU320. pdf? sequence $=1$

20. O'Brien BC, Harris IB, Beckman TJ, Reed DA, Cook DA. Standards for reporting qualitative research Acad Med [Internet]. 2014 [acesso em 2017 Set 4];89(9):1245-51. Disponível em: http://journals.lww.com/academicmedicine/ Fulltext/2014/09000/Standards_for_Reporting_Qualitative_Research A.21.aspx

21. Rede EQUATOR: Melhorando a qualidade e a transparência da pesquisa em saúde [acesso em 2017 Set 4]. Disponível em: http://www.equator-network.org

22. Núcleo de Tratamento e Estimulação Precoce. Quem Somos [acesso em 2017 Set 4]. Disponível em: http://www.nutep.org. br/portal/sobre-nos/quem-somos/. 
23. Krueger RA, Casey MA. Focus groups: a practical guide for applied research. $5^{\text {th }}$ ed. Los Angeles: SAGE; 2015.

24. Silva DLS, Knobloch F. A equipe enquanto lugar de formação: a educação permanente em um Centro de Atenção Psicossocial Álcool e outras drogas. Interface Comun Saúde Educ [Internet]. 2016 [acesso em 2017 Set 4];20(57):325-35. Disponível em: http://www.scielo.br/scielo.php?script=sci_arttext\&pid=S1414-32832016000200325\&lng=pt\&tlng=pt

25. Stewart DW, Shamdasani PN. Focus groups: theory and practice. $3^{\text {rd }}$ ed. Los Angeles: SAGE; 2014.

26. Araujo NB, Mandú ENT. Production of meanings among adolescents about self care during the pregnancy/ Produção de sentidos entre adolescentes sobre o cuidado de si na gravidez. Interface Comun Saúde Educ. 2016;20(57):363-75.

27. Bardin L. L'analyse de contenu. 2e éd. Paris: Presses Universitaires de France; 2013.

28. Huang YP, Chang MY, Chi YL, Lai FC. Health-related quality of life in fathers of children with or without developmental disability: the mediating effect of parental stress. Qual Life Res. 2014;23(1):175-83.

29. Czupryna K, Nowotny-Czupryna O, Nowotny J. Back pain in mothers of cerebral palsied children. Ortop Traumatol Rehabil [Internet]. 2014 [acesso em 2017 Set 4];16(5):497-505. Disponível em: http://899.indexcopernicus.com/abstracted. php?level $=5 \& \mathrm{ICID}=1128840$

30. Russell K, Oliver SE, Lewis L, Barfield WD, Cragan J, Meaney-Delman D, et al. Update: interim guidance for the evaluation and management of infants with possible congenital zika virus infection. MMWR Morb Mortal Wkly Rep [Internet]. 2016 [acesso em 2017 Set 4];65(33):870-8. Disponível em: http://www.cdc.gov/mmwr/volumes/65/wr/mm6533e2.htm

31. World Health Organization. Risk communication in the context of Zika virus [Internet]. Geneva: WHO; 2016 [acesso em 2017 Jul 3]. Disponível em: http://www.who.int/csr/resources/publications/zika/risk-communication/en/

32. Pan American Health Organization, World Health Organization. Zika virus infection: step by step guide on Risk Communication and Community Engagement. [Internet]. Geneva: WHO; 2017 [acesso em 2017 Jul 3]. Disponível em: http://iris.paho.org/xmlui/handle/123456789/33670

33. Pan American Health Organization, World Health Organization. Risk communication in the age of Zika virus [Internet]. Geneva: WHO; 2016 [acesso em 2017 Jul 3]. Disponível em: http://www.paho.org/hq/index.php?option=com _ docman\&task $=$ doc_view\&Itemid $=270 \&$ gid $=38456 \&$ lang $=$ en

34. Baker DE. Zika Virus and the Media. Hosp Pharm [Internet]. 2016 [acesso em 2017 Jul 3];51(4):275-6. Disponível em: http://archive.hospital-pharmacy.com/doi/10.1310/hpj5104-275.

35. Vonneilich N, Lüdecke D, Kofahl C. The impact of care on family and health-related quality of life of parents with chronically ill and disabled children. Disabil Rehabil. 2016;38(8):761-7.

36. Miner JJ. Congenital Zika virus infection: More than just microcephaly. Sci Transl Med. 2017 ;9(393):eaan8195.

37. Ministério da Saúde (BR), Secretaria de Atenção à Saúde. Protocolo de atenção à saúde e resposta à ocorrência de microcefalia: versão 3. Brasília: Ministério da Saúde; 2016 [acesso em 2017 Jul 3]. Disponível em: http://combateaedes. saude.gov.br/pt/profissional-e-gestor/orientacoes/140-diretrizes-de-estimulacao-precoce-criancas-de-zero-a-3-anos-comatraso-no-desenvolvimento-neuropsicomotor-decorrente-de-microcefalia

38. Vuorenmaa M, Perälä ML, Halme N, Kaunonen M, Åstedt-Kurki P. Associations between family characteristics and parental empowerment in the family, family service situations and the family service system. Child Care Health Dev. 2016;42(1):25-35.

39. Vuorenmaa M, Halme N, Perälä M-L, Kaunonen M, Åstedt-Kurki P. Perceived influence, decision-making and access to information in family services as factors of parental empowerment: a cross-sectional study of parents with young children. Scand J Caring Sci. 2016;30(2):290-302.

40. Brunoni D, Blascovi-Assis SM, Osório AAC, Seabra AG, Amato CAH, Teixeira MCTV, et al. Microcefalia e outras manifestações relacionadas ao vírus Zika: impacto nas crianças, nas famílias e nas equipes de saúde. Ciênc Saúde Coletiva. 2016;21(10):3297-302.

41. Lam W, Dawson A, Fowler C. Approaches to better engage parent-child in health home-visiting programmes. J Child Heal Care. 2017;21(1):94-102.

42. Centers for Disease Control and Prevention (US). Birth defects: facts about microcephaly [acesso em 2017 Jun 7]. Disponível em: http://www.cdc.gov/ncbddd/birthdefects/microcephaly.html

43. Centers for Disease Control and Prevention (US). Follow-Up Care: Zika Virus [acesso em 2017 Jun 7]. Disponível em: https://www.cdc.gov/zika/hc-providers/infants-children/follow-up-care.html. 
44. Garip Y, Ozel S, Tuncer OB, Kilinc G, Seckin F, Arasil T. Fatigue in the mothers of children with cerebral palsy. Disabil Rehabil. 2017;39(8):757-62.

45. Agrawal H, Wright OK, Carberry KE, Sexson Tejtel SK, Mery CM, Molossi S. Family perception of unmet support needs following a diagnosis of congenital coronary anomaly in children: results of a survey. Congenit Heart Dis [Internet]. 2017 [acesso em 2017 Jul 3]:1-5. Disponível em: http://doi.wiley.com/10.1111/chd.12473

46. Ansari NJR, Dhongade RK, Lad PS, Borade A, Yg S, Yadav V, et al. Study of parental perceptions on health \& social needs of children with neuro-developmental disability and it's impact on the family. J Clin Diagn Res. 2016;10(12):SC16-20.

47. Santos AB, Fonseca L. A relação subjetiva de mães de crianças com deficiência [monografia]. Salvador: Escola Bahiana de Medicina e Saúde Pública; 2016 [acesso em 2017 Jul 3]. Disponível em: http://www.repositorio.bahiana.edu.br/jspui/ handle/bahiana/324

48. Pelentsov L, Fielder A, Laws T, Esterman A. Development of the parental needs scale for rare diseases: a tool for measuring the supportive care needs of parents caring for a child with a rare disease. J Multidiscip Healthc [Internet]. 2016 [acesso em 2017 Jul 3];9:425-33. Disponível em: http://www.ncbi.nlm.nih.gov/pubmed/27672327

\section{Endereço para correspondência:}

Fabiane Elpídio de Sá

Universidade Federal do Ceará - UFC

Núcleo de Tratamento e Estimulação Precoce (NUTEP)

Rua Papi Junior, 1225

Bairro: Rodolfo Teófilo

CEP: 60430-230 - Fortaleza - CE - Brasil

E-mail: fabianeelpidio@yahoo.com.br 